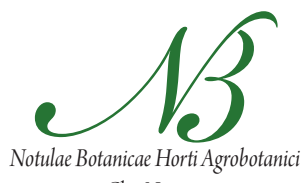

Cluj-Napoca

\title{
Genetic Diversity Within and Among Populations of Roseroot (Rhodiola rosea L.) Based on Molecular Markers
}

\author{
Zsuzsanna GYÖRGY1* Mária SZABÓ ${ }^{1}$, Dmitry BACHAROV², Andrzej PEDRYC \\ ${ }^{1}$ Corvinus University of Budapest, Department of Genetics and Plant Breeding, 44 Ménesi út Budapest \\ 1118, Hungary; zsuzsanna.gyorgy@uni-corvinus.hu ( ${ }^{*}$ corresponding author) \\ ${ }^{2}$ Komi Science Centre, Ural Division, Russian Academy of Sciences, Syktyvkar, Russia
}

\begin{abstract}
Rhodiola rosea $\mathrm{L}$. is a perennial adaptogenic medicinal plant found in cool climate of the northern hemisphere. The species is very diverse both in terms of morphological characteristics and in the content of the pharmacologically active substances. The genetic diversity of four geographically distant roseroot populations was studied with ISSR and SSR markers. Using 7 ISSR primers 64 DNA fragments were generated and $85,94 \%$ of those were found to be polymorphic, indicating high genetic variability at the species level (gene diversity $=0.33$, Shannon index $=0.48$ ). Lower level of diversity was detected at the population level (Shannon-index ranged from 0.2173 to 0.2696 ). Only four out of the eight SSR markers used were informative during this study. The primer pairs for these four SSR markers produced 25 fragments with an average of 6.25 putative alleles per locus. Observed heterozygosity ranged from 0.4 to 1.0 , whereas expected heterozygosity ranged from 0.47 to 0.84 . Cluster analysis based on both markers revealed the same groups, individuals clustered according to their geographic origin. The Southern-Uralian population was the most genetically isolated. ITS analysis was used for the determination whether these Southern-Uralian individuals belong to the same species.
\end{abstract}

Keywords: ISSR, ITS, molecular markers, Rhodiola rosea, SSR

\section{Introduction}

Rhodiola rosea L., commonly known as golden root or roseroot is a traditional adaptogen medicinal plant. Scandinavian, Eastern-European and Asian people have used it for centuries as general immune-stimulant. Roseroot belongs to the family Crassulaceae. It is a herbaceous plant with thick rhizome, which contains pharmacologically important secondary metabolites (Brown et al., 2002).

Rhodiola rosea displays a circumpolar distribution in the higher latitudes and elevations of the Northern hemisphere mainly in Asia and Europe (Brown et al., 2002; Furmanowa et al., 1995). According to Hegi (1963), its distribution in Europe extends from Iceland and the British Isles across Scandinavia as far south as the Pyrenees, the Alps, the Carpathian Mountains and other mountainous Balkan regions. Roseroot is highly variable both in phytochemical (Kurkin et al., 1988, Wiedenfeld et al., 2007) and in morphological aspects (Asdal et al. 2006; Ohba 1981, 1989).

According to Flora Europaea Rhodiola rosea has several synonyms like Sedum rhodiola DC., Sedum rosea (L.) Scop., Rhodiola arctica Boriss., Rhodiola iremelica Boriss., Rhodiola scopolii Simonk., Sedum scopolii Simonk. Rhodiola irmelica Boriss. is described in Flora USSR as an endemic species of Southern-Ural (1939). Analysis of the ITS (internal transcribed spacer) region is widely used in taxonomy because it is easy to amplify and has high degree of variation even between closely related species. Mayazumi and Ohba (2004) have performed a large scale analysis of the Cassulaceae family, but no information is available about $R$. iremelica.

For genetic diversity studies mostly inter simple sequence repeats (ISSR) have been applied in the genus Rhodiola. Xia et al. (2005) studied the genetic variation within and among populations of Rhodiola alsia and later (Xia et al., 2007) of Rhodiola chrysanthemifolia native to the Tibetan Plateau. Lei et al. (2006) explored the genetic variation in Rhodiola crenulata from the Hengduan Mountains. Finnish Rhodiola rosea populations were analysed by György et al. (2009). Yanbaev et al. (2007) studied Rhodiola iremelica populations in the Southern-Urals with isoenzymes. Elameen et al. (2008) investigated using AFLP (Amplified Fragment Length Polymorphisms) technique the genetic diversity in a Norwegian germplasm collection. Meng et al. (2007) used AFLP for analysing intra-specific genetic variation in the genus Rhodiola and the same method was used by Wang et al. (2009) for studying the genetic diversity of Rhodiola rosea populations from Tianshan Mountain. Recently Kozyrenko et al. (2011) analysed the genetic structure of Rhodiola rosea accessions mostly of Russian origin using ISSR technique.

In 2009 Zini et al. (2009) published eight microsatellite sequences (simple sequence repeats, SSR) of Rhodiola 
rosea and flanking primer pairs specifically designed for this species. These primers were tested on two Rhodiola rosea populations from the Trentino Alps. Four out of these primers were also used by Kylin (2010) for evaluating genetic diversity of roseroot plants collected in Sweden, Greenland and Faroe Islands.

The aim of the present work was to characterize interand intrapopulation genetic variability among selected roseroot individuals from Northern-Urals, Southern-Urals, Novaya Zemlya and Altai Mountain populations using the eight available SSR markers and comparing these results with the results of ISSR method. The obtained data was compared against the genetic variability detected by the same markers in the roseroot plants studied from the Trento region, Italy by Zini et al. (2009). An effort was made to clarify whether Southern-Uralian roseroot population considered to be Rhodiola iremelica is really a separate species or belongs to Rhodiola rosea.

\section{Materials and methods}

\section{Plant material and DNA preparation}

Rhodiola rosea plants were provided by the Institute of Biology, Komi Science Centre, Ural Division, Russian Academy of Sciences, Syktyvkar, Russia. Roseroot plants were collected in the Northern-Ural Mountains, Southern-Ural Mountains, in Novaya Zemlya and in the Altai Mountain (Fig. 1). The collected plants were cultivated in the experimental field of Syktyvkar University. Due to difficulties of transporting plant material only 5 plants were included in the study from each population, all together 20 individuals. The plant material was frozen in liquid nitrogen and was stored in $-80^{\circ} \mathrm{C}$ until used. DNA was ex- tracted from the frozen leaves according to a CTAB-based protocol (Pirttilä et al., 2001). DNA concentration and quality was assessed using NanoDrop spectrophotometer (BioScience, Hungary) and visualized on 1\% agarose gel.

\section{PCR amplification of SSR and ISSR markers}

PCR was performed in $25 \mu \mathrm{l}$ reaction volume containing 20-80 ng DNA, 10 $\times$ PCR reaction buffer, 2.5 $\mathrm{mM} \mathrm{MgCl}, 2 \mathrm{mM} \mathrm{dNTP} \mathrm{mix,} 2.5 \mu \mathrm{mol}$ of each 5' and 3' end primers, 1 unit of Taq DNA polymerase (Fermentas, Szeged, Hungary) and sterile distilled water. Eight SSR primer pairs, designed specifically for roseroot by Zini et al. (2009) were used for the DNA amplification. The forward primers were fluorescently labelled (FAM). Seven ISSR primers from the UBC primer set \#9 developed at the University of British Columbia, (Canada) (BC807, BC809, BC840, BC841, BC857, BC885 and BC888) were chosen based on preliminary experiments. PCR was carried out in a PTC 200 thermocycler (MJ Research, Budapest, Hungary) using touchdown strategy as described in the paper of Zini et al. (2009) in the case of SSR markers. For the amplification of ISSR fragments the following program was used: initial denaturation at $94^{\circ} \mathrm{C}$ for $4 \mathrm{~min}$; followed by 40 cycles of $94^{\circ} \mathrm{C}$ for $60 \mathrm{~s}, 49^{\circ} \mathrm{C}$ for $90 \mathrm{~s}, 72^{\circ} \mathrm{C}$ for $90 \mathrm{~s}$; and a final extension at $72^{\circ} \mathrm{C}$ for $7 \mathrm{~min}$.

The PCR products were electrophoresed on a $1 \%$ (w/v) ethidium bromide-stained agarose gel (SeaKem LE Agarose, Lonza, Rockland, ME USA) in 1xTBE buffer with xylencyanol loading buffer to verify the occurrence of the amplification. For the ISSR analysis PCR products were separated for $2 \mathrm{~h}$ at $120 \mathrm{~V}$. Amplified fragments were scored visually for presence (1) or absence (0) and the result were summarised in MS Excel table.

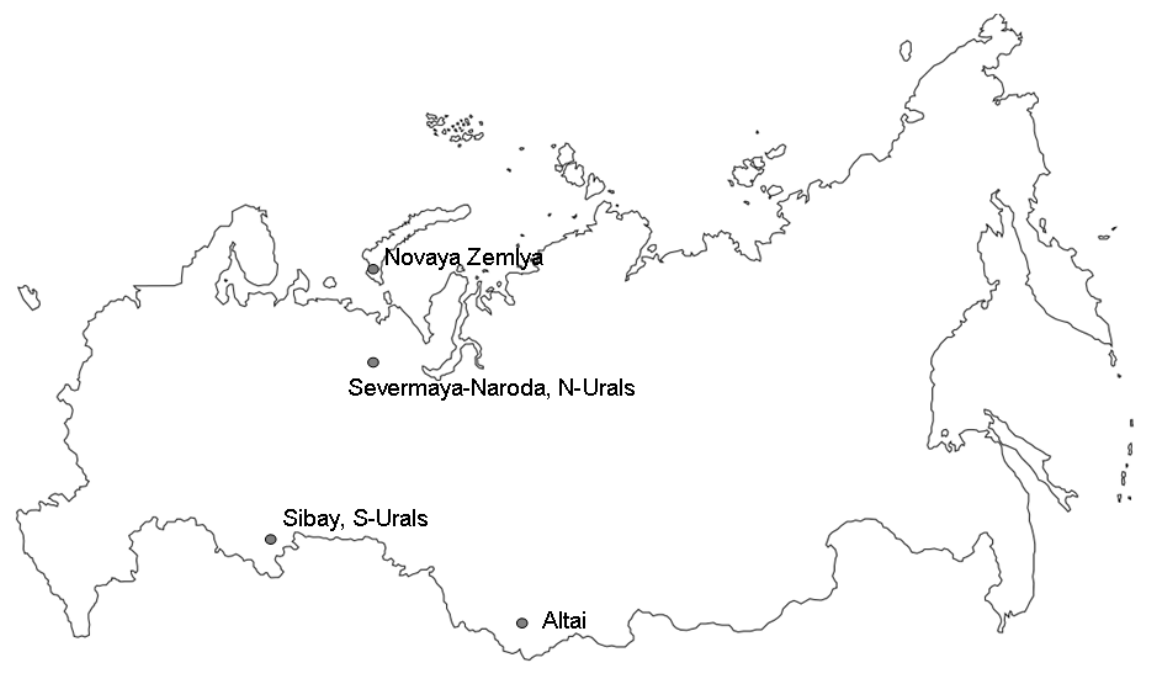

Fig. 1. Map showing the approximate locations of the four examined roseroot populations 
268

The amplified SSR fragments were separated on $8 \%$ polyacrylamide gel at $80 \mathrm{~W}\left(55^{\circ} \mathrm{C}\right)$ for $4 \mathrm{~h}$, and stained with a simple silver staining method (Bassam and Gresshoff, 2007). Amplified fragments were scored visually. To determine the exact size of different fragments, 3 from each detected fragment sizes were run in an automated sequencer ABIPRISM 3100 Genetic Analyzer (Applied Biosystems, Budapest, Hungary). Band scoring was analysed using Peak Scanner software 1.0 (Applied Biosystems, 2006).

Genetic relatedness among genotypes was studied by UPGMA (Unweighted Pair Group Method with Arithmetic averages) cluster analysis using Popgene version 1.32 (1997). Also Popgene was used to estimate expected $\left(\mathrm{H}_{\mathrm{e}}\right)$, observed $\left(\mathrm{H}_{\mathrm{o}}\right)$ heterozygosity, Nei's (1978) gene diversity and Shannon's Information Index (I) for co-dominant marker data (SSR). For dominant marker data (ISSR), Popgene was used to estimate number of polymorphic bands, percentage of polymorphic bands, Nei's gene diversity (h) and Shannon's Information Index (I). For all individuals Hamming distance was calculated with PASSaGE 2 (Rosenberg and Anderson, 2011) in case of both marker method. The distance matrices were compared with Mantel test also performed with PASSaGE 2.

\section{PCR amplification of ITS regions}

The internal transcribed spacer region includes the two internal transcribed spacers (ITS1, ITS2) and the $5.8 \mathrm{~S}$ gene of the $18 \mathrm{~S} / 26 \mathrm{~S}$ nuclear ribosomal DNA (rDNA) repeats. This region was amplified using the primers ITS-LEU (Baum et al., 1998) and ITS4 (White et al., 1990). PCR mix was the same as described earlier. The PCR program started at $94^{\circ} \mathrm{C}$ for $4 \mathrm{~min}$, followed by 30 cycles of $94^{\circ} \mathrm{C}$ for $30 \mathrm{sec}, 50^{\circ} \mathrm{C}$ for $1 \mathrm{~min}$ and $72^{\circ} \mathrm{C}$ for $1 \mathrm{~min}$, followed by an additional 7 min extension at $72^{\circ} \mathrm{C}$. The PCR products were separated on a $1 \%(\mathrm{w} / \mathrm{v})$ ethidium bromide-stained agarose gel in $1 \times \mathrm{TBE}$ buffer with xylencyanol loading buffer to verify the occurrence of the amplification. Fragment lengths were estimated by comparison with the 1-kb DNA ladder (Promega, Madison, USA).
The gel-purified PCR products (EZ-10 Spin Column DNA, Gel Extraction Kit, Bio Basic INC, Biocenter, Hungary) were directly used in the sequencing reaction. Sequencing used the BigDye Terminator Cycle Sequencing Kit (PE Applied Biosystems, Warrington, UK) and was performed in an automated sequencer ABIPRISM 3100 Genetic Analyzer (Applied Biosystems, Budapest, Hungary). Both strands were sequenced and the same primers (ITS-LEU and ITS4) were used as in the PCR.

DNA sequences were compared using BLASTN at NCBI and ClustalW program (Thompson et al. 1994), and the aligned sequences were edited with BioEdit v.7.0.9.0.

\section{Results}

\section{SSR markers}

Amplification was successful with 7 out of the 8 available roseroot SSR primers. The numbers of alleles per locus amplified in course of the study are presented in Tab. 1 . Primers for marker RRE4 in most samples failed to amplify genomic DNA. Primer pair for marker RRF4 amplified mostly only one allele per locus indicating homozigosity for that allele or the presence of null alleles. The primers for RRE9 and RRF3 amplified monomorphic fragments for the tested plants (146 and 155; 133 and $143 \mathrm{bp}$ respectively). Therefore only 4 (RRC10, RRD6, RRE2, RRE3) out of the 8 markers were informative during the study. The primer pairs for these four SSR markers produced 25 fragments. The number of alleles per locus ranged from 2 (RRE9 and RRF3) to 8 (RRC10). Sizes ranged from 103 (RRF4) to 185 bp (RRE2) (Tab. 2).

Genetic diversity parameters are presented in Tab. 2. Observed heterozygosity $\left(\mathrm{H}_{\mathrm{o}}\right)$ ranged from 0.4 to 1.0 , whereas expected heterozygosity $\left(\mathrm{H}_{\mathrm{c}}\right)$ (genetic diversity) ranged from 0.47 at RRD6 for Altai to 0.84 at RRC10 for Altai population.

Genetic relationships among the studied populations of various origins are shown in Fig. 2. According to this dendrogram the $\mathrm{S}$-Uralian population forms the most distinct group from the others.

Tab. 1. Obtained allele numbers and allele sizes at the examined loci. The brackets mean that amplification was not successful with $100 \%$ of the samples

\begin{tabular}{cccc}
\hline Locus name & $\begin{array}{c}\text { No. of alleles obtained } \\
\text { in this study }\end{array}$ & $\begin{array}{c}\text { Expected size range, based on } \\
\text { Zini } \text { et al. 2009(in bp) }\end{array}$ & $\begin{array}{c}\text { Obtained allele size } \\
\text { (in bp) }\end{array}$ \\
\hline RRC10 & 7 & $146-164$ & $140-158$ \\
RRD6 & 6 & $168-186$ & $166-182$ \\
RRE2 & 8 & $161-182$ & $155-185$ \\
RRE3 & 4 & $173-183$ & $173-183$ \\
RRE4 & $2(-)$ & $146-149$ & $146-149$ \\
RRE9 & 2 & $143-161$ & $146-155$ \\
RRF3 & 2 & $121-137$ & $133-143$ \\
RRF4 & $2(-)$ & $103-118$ & $103-115$ \\
\hline
\end{tabular}


Tab. 2. Genetic parameters assessed for the four roseroot population based on SSR markers

\begin{tabular}{|c|c|c|c|c|c|}
\hline Locus & $\mathrm{H}_{0}$ & $\mathrm{H}_{e}$ & Nei & Ave Het & I \\
\hline \multicolumn{6}{|c|}{ N-Urals } \\
\hline RRC10 & 1.00 & 0.73 & 0.66 & 0.66 & 1.19 \\
\hline RRD6 & 0.40 & 0.62 & 0.56 & 0.56 & 0.95 \\
\hline RRE2 & 1.00 & 0.71 & 0.64 & 0.64 & 1.17 \\
\hline RRE3 & 1.00 & 0.73 & 0.66 & 0.66 & 1.19 \\
\hline Mean & 0.85 & 0.70 & 0.63 & 0.63 & 1.13 \\
\hline $\mathrm{SD}$ & 0.30 & 0.05 & 0.05 & 0.05 & 0.12 \\
\hline \multicolumn{6}{|c|}{ S-Urals } \\
\hline RRC10 & 0.60 & 0.69 & 0.62 & 0.62 & 1.03 \\
\hline RRD6 & 1.00 & 0.73 & 0.66 & 0.66 & 1.22 \\
\hline RRE2 & 1.00 & 0.78 & 0.70 & 0.70 & 1.28 \\
\hline RRE3 & 1.00 & 0.73 & 0.66 & 0.66 & 1.19 \\
\hline Mean & 0.90 & 0.73 & 0.66 & 0.66 & 1.18 \\
\hline SD. & 0.20 & 0.04 & 0.03 & 0.03 & 0.11 \\
\hline \multicolumn{6}{|c|}{ Altai } \\
\hline RRC10 & 1.00 & 0.84 & 0.76 & 0.76 & 1.50 \\
\hline RRD6 & 0.60 & 0.47 & 0.42 & 0.42 & 1.61 \\
\hline RRE2 & 1.00 & 0.71 & 0.64 & 0.64 & 1.05 \\
\hline RRE3 & 1.00 & 0.56 & 0.50 & 0.50 & 0.69 \\
\hline Mean & 0.90 & 0.64 & 0.58 & 0.58 & 0.97 \\
\hline $\mathrm{SD}$ & 0.20 & 0.17 & 0.15 & 0.15 & 0.41 \\
\hline \multicolumn{6}{|c|}{ Novaya Zemlya } \\
\hline RRC10 & 1.00 & 0.64 & 0.58 & 0.58 & 0.94 \\
\hline RRD6 & 1.00 & 0.64 & 0.58 & 0.58 & 0.94 \\
\hline RRE2 & 1.00 & 0.82 & 0.74 & 0.74 & 1.47 \\
\hline RRE3 & 1.00 & 0.69 & 0.62 & 0.62 & 1.03 \\
\hline Mean & 1.00 & 0.70 & 0.63 & 0.63 & 1.10 \\
\hline SD & 0.00 & 0.08 & 0.08 & 0.08 & 0.25 \\
\hline
\end{tabular}

SD - standard deviation

\section{ISSR markers}

The selected 7 primers generated 64 bands, corresponding to an average of 9.14 bands per primer. An example for ISSR gel is presented in Fig. 3. The number of population specific bands (either being specifically present or specifically missing) ranged from 1 to 7 . The least variable band pattern was generated with primer $\mathrm{BC} 857$ ( 1 population-specific band out of 9), while the most variable band pattern was generated with primer BC840 (6 population-specific band out of 8 ). At the population level the Shannon-index was 0.48 and the percentage of polymorphic loci (PPL) was $85.94 \%$. The comparison of the value of the Shannon-index and PPL in the 4 habitats is shown in Tab. 3. As indicated by these parameters, the highest level of variability occurred in New Land population $(\mathrm{PPL}=46.88 \% ; \mathrm{I}=0.2696)$, whereas the lowest level in the $S$-Uralian population $(\mathrm{PPL}=37.5 \%$; $\mathrm{I}=0.2173)$. Genetic relationships among the studied individuals of various origins are shown in Fig. 4. Similarly to the dendrogram shown in Fig. 2, the S-Uralian population formed the most distinct group from the other populations.

\section{Comparison of the variability based on the two marker methods}

Mantel test $(Z=84.59)$ was performed for the comparison of the variability data gained with the two different marker system. The correlation was found to be 0.24 $(p=0.001)$, the Mantel test was highly significant. Based on this result the two marker methods found the same individuals to be close or to be distant. This confirms the two denrograms (Fig. 2 and 4 ) being very similar.

\section{Amplification and sequencing of the ITS region}

The S-Uralian roseroot population clustered to a separate group in both dendrograms drawn based on the SSR and ISSR data (Fig. 2 and 3). Sequencing of the ITS region of all individuals from this population and also 2-3 individuals from the others was undertaken to clarify if the S-Uralian population belongs to Rhodiola rosea or possibly to Rhodiola iremelica (Yanbaev et al., 2007). The ITS-LEU and ITS 4 primers amplified a $690 \mathrm{bp}$ fragment from all samples. Fig. 4 shows the alignment of these se-
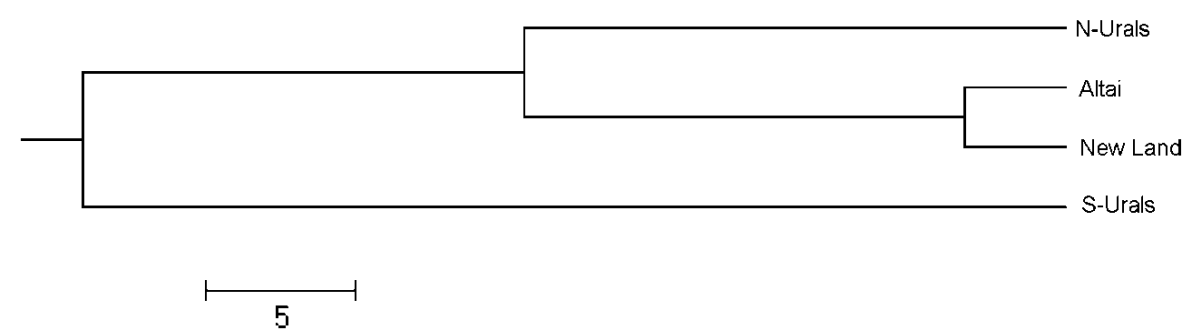

Fig. 2. Dendrogram of the four roseroot populations assayed in this study generated by UPGMA cluster analysis based on the similarity matrix obtained using Nei's genetic distance based on SSR data (Nei, 1978)

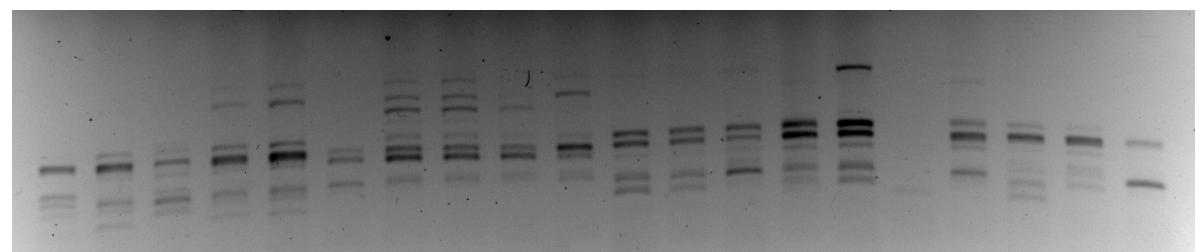

Fig. 3. Gel photo of the electrophoresis of the amplicons generated with the ISSR primer BC 885 
Tab. 3. Genetic variability of roseroot populations based on 7 ISSR marker

\begin{tabular}{cccccc}
\hline Population & $\begin{array}{c}\text { Number of } \\
\text { polimorfic bands }\end{array}$ & $\begin{array}{c}\text { \% of polimorphic } \\
\text { bands }\end{array}$ & $\begin{array}{c}\text { Gene diversity } \\
\text { (h) }\end{array}$ & $\begin{array}{c}\text { Shannon-index } \\
\text { (SI) }\end{array}$ & St. dev. \\
\hline N-Urals & 29 & $45.31 \%$ & 0.18 & 0.26 & 0.22 \\
S-Urals & 24 & $37.50 \%$ & 0.15 & 0.25 & 0.29 \\
Altai & 28 & $43.75 \%$ & 0.17 & 0.27 & 0.29 \\
Novaya Zemlya & 30 & $46.88 \%$ & 0.18 & 0.48 & 0.30 \\
Total & 55 & $85.94 \%$ & 0.33 & 0.22 \\
\hline
\end{tabular}

Tab. 4. Comparision of the obtained allel numbers at the examined locuses found by Zini et al. (2009), Kylin (2010) and in the present study. The brackets mean that amplification was not successful with $100 \%$ of the samples

\begin{tabular}{cccc}
\hline Locus name & $\begin{array}{c}\text { No. of alleles found by } \\
\text { Zini } \text { et al. (2009) }\end{array}$ & $\begin{array}{c}\text { No. of alleles found } \\
\text { by Kylin (2010) }\end{array}$ & $\begin{array}{c}\text { No. of alleles obtained } \\
\text { in this study }\end{array}$ \\
\hline RRC10 & 4 & 4 & 7 \\
RRD6 & 5 & 4 & 6 \\
RRE2 & 5 & - & 8 \\
RRE3 & 3 & 2 & 4 \\
RRE4 & 2 & - & $2(-)$ \\
RRE9 & 3 & - & 2 \\
RRF3 & 3 & - & $2(-)$ \\
RRF4 & 3 & & \\
\hline
\end{tabular}

quences to ITS sequence from other Rhodiola species $(R$. rosea GQ374198.1, $R$. yunnanensis AB088602.1, $R$. wallichiana AB088607.1, $R$. macrocarpa AB088590.1, $R$. heterodonta $\mathrm{AB} 088596.1, R$. fastigiata $\mathrm{AB} 088594.1$ and $R$. chrysanthemifolia AB088606.1) available in the NCBI genbank. The ITS sequences of the present study are almost identical as seen in Fig. 5.

\section{Discussion}

The aim of the present study was to compare the SSR and ISSR methods for the analysis of the genetic diversity of Rhodiola rosea. Both SSR and ISSR markers revealed genetic diversity within the examined populations of roseroot.

Genetic variability within the populations detected with the ISSR method was somewhat higher than in the study of Kozyrenko et al. (2011) where eight primers were used. Shannon index ranged between $0.22-0.27$ while in the study of Kozyrenko et al. (2011) it ranged between 0.16-0.26. The genetic diversity observed among the populations was much higher in the present study. Shan- non index was 0.48 while in the study of Kozyrenko et al. (2011) it was just 0.29 . This big alteration can be the result of the fact that the examined populations in this study are located at much diverse latitude, while Kozyrenko et al. (2011) took samples from more similar latitude, rather than the difference in the used markers, since half of the primers used are the same in the two studies. Earlier two Finnish roseroot populations were compared with five primers (György et al., 2011) and Shannon-indexes of 0.3129 and 0.2316 were calculated within the two populations, while 0.3385 among the populations. Generally all these Shannon index values are similar to those of $R$. crenulata from the Hengduan Mountains (0.168-0.325, 12 primers), (Lei et al., 2006) and somewhat higher than of $R$. alsia (0.0729-0.2235, 13 primers), (Xia et al., 2005) and $R$. chrysanthemifoila (0.0833-0.2415, 13 primers), (Xia et al., 2007) in the Tibetian Plateau.

Zini et al. (2009) developed the eight SSR markers available for Rhodiola rosea. The genetic diversity of two Italian roseroot populations was examined as validation of these markers. Kylin (2010) used four out of these SSR

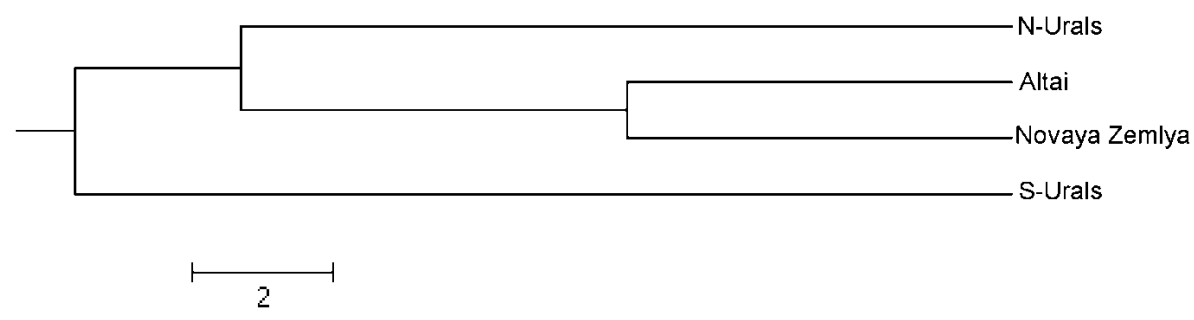

Fig. 4. Dendrogram of the 20 roseroot samples of 4 populations assayed in this study generated by UPGMA cluster analysis based on the similarity matrix obtained using Nei's genetic distance based on ISSR data (Nei, 1978) 

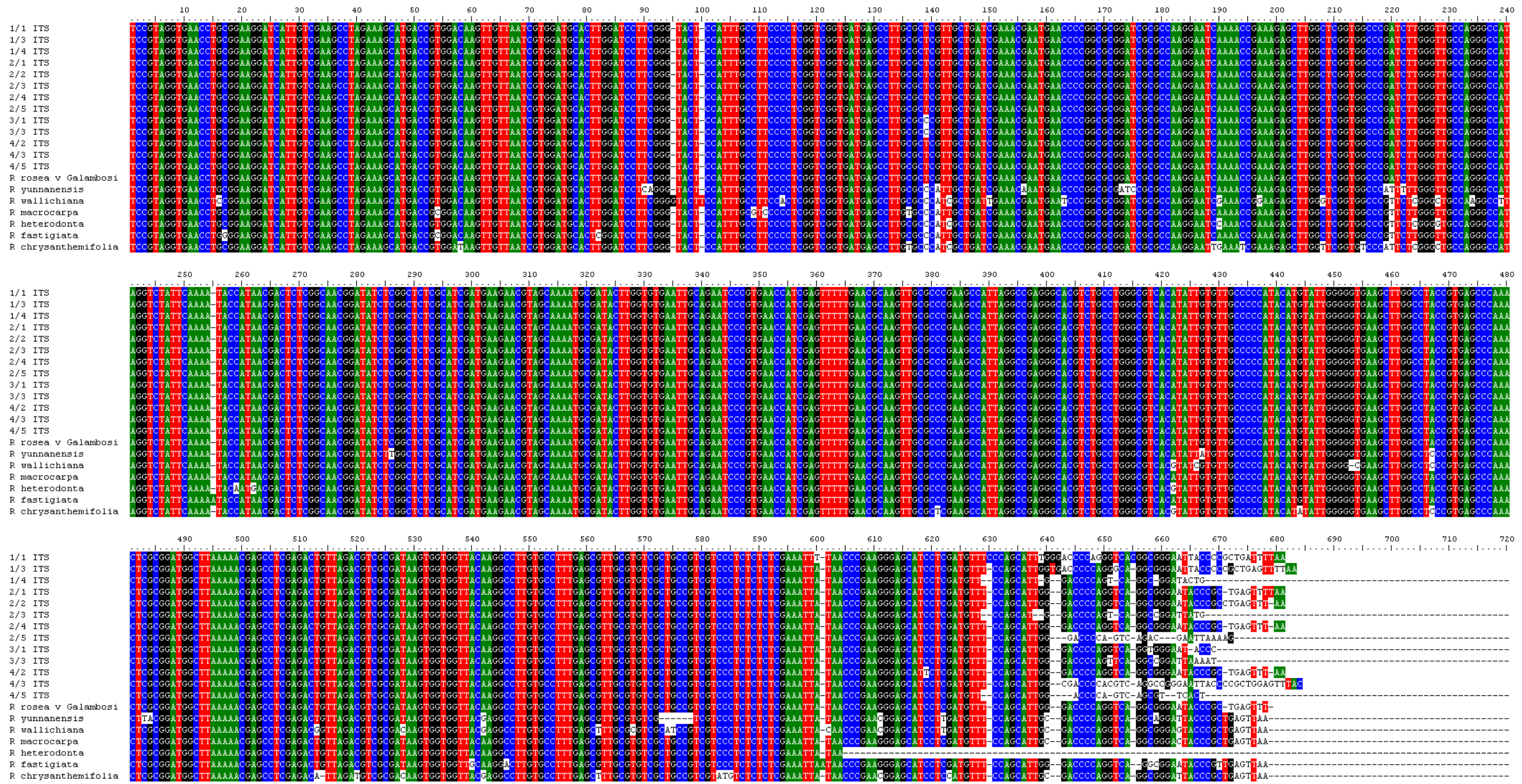

Fig. 5. Alignment of ITS sequences of 3 individuals from N-Uralian population $(1 / 1,1 / 3,1 / 4), 5$ individuals from S-Uralian population $(2 / 1,2 / 2,2 / 3,2 / 4,2 / 5)$, 2 individuals from Altaian population (3/1,3/3), 3 individuals from New Land population and further Rhodiola ITS sequences found in the NCBI genbank: $R$. rosea, $R$. yunnanensis, $R$. wallichiana, $R$. macrocarpa, $R$. heterodonta, $R$. fastigiata and $R$. chrysanthemifolia 
272

markers for exploring genetic diversity in the Swedish Rhodiola rosea collection (NordGen).

As it can be seen from Tab. 4, RRC10, RRD6 and RRE2 loci showed the highest polymorphism. RRE4, RRE9, RRF3 and RRF4 are either monomorphic (with two alleles) or many times even failed amplification. Higher number of alleles detected in this study indicates higher genetic diversity in the studied populations compared to the study of Zini et al. (2009) and Kylin (2010). Observed heterozygosity $(\mathrm{Ho})$ ranged from 0.4 to 1.0 , whereas expected heterozygosity ( $\mathrm{He}$ ) (genetic diversity) ranged from 0.4667 at RRD6 for Altai to 0.8444 at RRC10 for Altai. Lowest and highest observed heterozygosity for the same loci analysed by Zini et al. (2009) ranged from 0.091 at RRE3 to 0.760 at RRF3, and lowest value for expected heterozygosity was achieved at RRE3 (0.165) and highest value was at RRC10 (0.661). In the study of Kylin (2010) observed heterozygosity ranged from 0.0 at RRE9 to 1.0 at RRC10, while expected heterozygosity ranged from 0.198 at RRE3 to 0.733 at RRC10. Both expected and observed heterozygosity were higher in all four populations than reported previously for the same primer set, which indicates higher genetic variation in the studied roseroot populations.

The highest genetic diversity was found in the Novaya Zemlya population, while the lowest in the S-Uralian population both with the used SSR and ISSR markers (Tab. 3 and 4). The Novaya Zemlya population is the northernmost population examined so far. The optimal environmental circumstances may favour the maintenance of high genetic variability.

The S-Uralian population according to Yanbaev et al. (2007) is an endemic plant (R. iremelica). According to our results these plants form a clearly separated cluster on the dendrograms based both on SSR and ISSR markers. ITS sequence analysis was performed. Ishmuratova (2004) and Yanbaev et al. (2007) has written about these plants as $R$. iremelica. Borissova (1939) described $R$. iremelica in Flora USSR as new species. The difference between $R$. iremelica and $R$. rosea are the shape of the leaves and the size of the seeds. As mentioned earlier $R$. rosea displays high morphological variability. Flora Europaea states that $R$. iremelica is only a synonym for $R$. rosea (http://rbg-web2. rbge.org.uk/FE/fe.html). Mayuzumi and Ohba (2004) examined the phylogenetic position of Eastern-Asian $\mathrm{Se}$ doideae and Gontcharova et al. (2006) has studied members of the Sedoideae subfamily based on ITS region. The ITS region sequences of different $R$ hodiola species gained in their studies were used in the alignment together with the sequences of the present study. Unfortunately no sequence data is available for $R$. iremelica. In those positions where Rhodiola species differ no alteration can be observed among the ITS sequences of the individuals from the four examined populations, which supports the $S$-Uralian population being Rhodiola rosea or a subspecies of it. Further studies are needed to clarify this issue.
In conclusion, using ISSR markers and SSR markers recently developed for roseroot we were able to assess genetic diversity of roseroot populations of different geographical origin. Both marker systems revealed similar results. However according to our results only four out of the eight SSR primers are feasible (RRC10, RRD6, RRE2, RRE3). Developing more roseroot specific SSR markers would be needed for more accurate studies.

\section{Acknowledgement}

This study was financed by Hungarian Scientific Research Fund (OTKA PD 83728) and the Hungarian National Development Agency with TÁMOP- 4.2.1/B09/1/KMR-2010-0005 and TÁMOP -4.2.2/B-10/12010-0023 projects. Dr. Márta Ladányi is acknowledged for the assistance in performing the Mantel-test.

\section{References}

Asdal A, Galambosi B, Olsson K, Wedelsback Bladh K, Porvaldsdóttir E (2006). Spice-and Medicinal Plants in the Nordic and Baltic Countries. Conservation of Genetic Resources 94-104.

Bassam BJ, Gresshoff PM (2007). Silver staining DNA in polyacrylamide gels. Nature Protocols 2(11):2649-2654.

Baum DA, Small RL, Wendel JF (1998). Biogeography and floral evolution of baobabs (Adansonia, Bombacaceae) as inferred from multiple data sets. Systematic Biology 47(2):181-207.

Borissova AG (1939). The family Crassulaceae, p. 472. In: KomarovVL (Ed.). Flora of USSR, vol. 9. Academiae Scientiarum URSS, Moscow, Leningrad.

Brown RP, Gerbarg PL, Ramazanov Z (2002). Rhodiola rosea, a phytomedicinal overview. Herbal Gram 56:40-52.

Elameen A, Klemsdal SS, Dragland S, Fjellheim S, Rognli OA (2008). Genetic diversity in a germplasm collection of roseroot (Rhodiola rosea) in Norway studied by AFLP. Biochemical Systematics and Ecology 36(9):706-715.

Furmanowa M, Oledzka H, Michalska M, Sokolnicka I, Radomska D (1995). Rhodiola rosea L. (Roseroot): In vitro regeneration and the biological acivity of roots. Biotechnology in Agriculture and Forestry Vol. 33, Medicinal and Aromatic Plants VIII:412-426.

Gontcharova SB, Artyukova EV, Gontcharov AA (2006). Phylogenetic relationships among members of the subfamily Sedoideae (Crassulaceae) inferred from the ITS region sequences of nuclear rDNA. Russan Journal of Genetics 42(6):654-661.

György Z, Derzsó E, Galambosi B (2009). Finnországi Rhodiola rosea populációk diverzitásának vizsgálata ISSR markerekkel. Lippay János - Ormos Imre - Vas Károly Tudományos Ülésszak, 28-30 October, 2009, Budapest, Hungary.

György Z, Derzsó E, Galambosi B, Pedryc A (2011). Genetic diversity of Finnish Rhodiola rosea populations based on SSR and ISSR analysis. Acta Horticulturae 955:197-202. 
Hegi G (1963). Rhodiola, Rosenwurz, p. 99-102. In: Hegi G (Ed.). Illustrierte Flora von Mitteleuropa. Band IV/2, Liefering 2/3. Zweite völlig neubearbeitete edn., Hamburg/ Berlin.

Kozyrenko MM, Gontcharova SB, Gontcharov AA (2011). Analysis of the genetic structure of Rhodiola rosea (Crassulaceae) using inter-simple sequence repeat (ISSR) polymorphisms. Flora 206:691-696.

Kurkin VA, Zapesochanaya GG, Nukhimovskii EL, Klimakhin GI (1988). Chemical composition of rhizomes of Mongolian Rhodiola rosea L. population introduced into districts near Moscow. Khimiko-farmatsevticheskij Zhurnal 22(3):324326.

Kylin M (2010). Genetic diversity of Roseroot (Rhodiola rosea L.) from Sweden, Greenland and Faroe Islands. Diploma thesis, Alnarp, Sweden, MSc thesis http://stud.epsilon.slu. se/2049/

Lei Y, Gao H, Tsering T, Shi S, Zhong Y (2006). Determination of genetic variation in Rhodiola crenulata from the Hengduan Mountains Region, China using inter-simple sequence repeats. Genetics and Molecular Biology 29(2):339-344.

Mayuzumi S, Ohba H (2004). The Phylogenetic Position of Eastern Asian Sedoideae (Crassulaceae) Inferred from Chloroplast and Nuclear DNA Sequences. Systematic Botany 29(3):587-598.

Meng LH, Yang R, Abbott RJ, Miehe G, Hu TH, Liu JQ (2007). Mitochondrial and chloroplast phylogeography of Picea crassifolia Kom. (Pinaceae) in the Qinghai-Tibetan Plateau and adjacent highlands. Molecular Ecology 16(19):41284137.

Nei M (1978). Estimation of average heterozygosity and genetic distance from a small number of individuals. Genetics 89:583-590.

Ohba H (1981). A revision of Asiatic species of Sedoideae (Crassulaceae). Part 2. Rhodiola (subgen. Rhodiola, sect. Rhodiola). J. Fac. Sci. Univ. Tokyo 13:65-119, Section 3.

Ohba H (1989). Biogeography of the genus Rhodiola (Crassulaceae), with special reference to the floristic interaction between the Himalaya and Arctic region, p. 115133. In: Ohba H. (Ed.). Current Aspects of Biogeography in West Pacific and East Asian Regions, vol. 1. University of Tokyo, Tokyo.
PirctïaM, HirsikorpiM, Käm...... 273 (2001) Kirsorpi M, Kämäränen T, Jaakola L, Hohtola A (2001). DNA isolation methods for medicinal and aromatic plants. Plant Molecular Biology Reporter 19:273a-f.

Rosenberg MS, Anderson CD (2011). PASSaGE: Pattern Analysis, Spatial Statistics and Geographic Exegesis. Version 2. Methods in Ecology \& Evolution 2(3):229-232.

Thompson JD, Higgins DG, Gibson TJ (1994). CLUSTALW: improving the sensitivity of progressive multiple sequence alignment through sequence weighting, position-specific gap penalties and weight matrix choice. Nucl Acids Res 22:4673-4680.

Wang Q, Ruan X, Jiang H, Meng Q, Wang L (2009). Genetic diversity of different geographical populations of Rhodiola rosea based on AFLP markers. China Journal of Chinese Materia Medica 34:2279.

White TJ, Birns T, Lee S, Taylor J (1990). Amplification and direct sequencing of fungal ribosomal RNA genes for phylogenetic. PCR protocols: A guide to methods and applications. Academic Press, San Diego.

Wiedenfeld H, Dumaa M, Malinowski M, Furmanowa M, Narantuya S (2007). Phytochemical and analytical studies of extracts from Rhodiola rosea and Rhodiola quadrifida. Pharmazie 62(4):308-11.

Xia T, Shilong C, Shengyun C (2005). Genetic Variation Within and Among Populatin of Rhodiola alsia (Crassulaceae) Native to the Tibetan Plateau as Detected by ISSR Markers. Biochemical Genetics 43:87-99.

Xia T, Shilong C, Shegyun C, Defang Z, Dejun Z, Qingbo G, Xuejun G (2007). ISSR analysis of genetic diversity of the Qinghai-Tibet Plateau endemic Rhodiola chrysanthemifolia (Crassulaceae). Biochemical Systematics and Ecology 35:209-214.

Yanbaev YA, Bairamgulov NR, Redkina NN, Mullagulov RY (2007). Differentiation among Populations of the Rhodiola iremelica Boriss. (Grassulaceae) in the Southern Urals. Russian Journal of Genetics 43(11):1314-1318.

Zini E, Clamer M, Passerotti S, Vender C, Vendramin GG, Komjanc M (2009). Eight novel microsatellite DNA markers in Rhodiola rosea L. Conservation Genetics 10(5):13971399. 